\title{
Engaging multiple audiences: Challenges and strategies in complex food systems projects
}

Kathryn Z. Ruhf ${ }^{a *}$

Northeast Sustainable Agriculture Working Group



Kristen Devlin ${ }^{b}$

Northeast Regional Center for Rural Development

Kate Clancy ${ }^{\mathrm{c}}$

Food Systems Consultant

Linda Berlin ${ }^{\mathrm{d}}$

University of Vermont Center for Sustainable Agriculture

Anne Palmer ${ }^{\mathrm{e}}$

Center for a Livable Future, Johns Hopkins Bloomberg School of Public Health

Submitted May 22, 2017 / Revised September 4, 2017 / Accepted September 4, 2017 /

Published online December 20, 2017

Citation: Ruhf, K. Z., Devlin, K., Clancy, K., Berlin, L., \& Palmer, A. (2017). Engaging multiple audiences:

Challenges and strategies in complex food systems projects. Journal of Agriculture, Food Systems, and Community

Development, 7(4), 179-185. http://dx.doi.org/10.5304/jafscd.2017.074.016

Copyright (C) 2017 by New Leaf Associates, Inc.

\section{Abstract}

Complex projects must manage many challenges, including how to communicate about them. In this

a * Corresponding author: Kathryn Z. Ruhf, Northeast Sustainable Agriculture Working Group; 31 Jackson Street; Belchertown, MA 01007 USA; kzruhf@,verizon.net

${ }^{b}$ Kristen Devlin, Northeast Regional Center for Rural Development, Penn State University, 7 Armsby Building, University Park, PA 16802 USA; krd111@psu.edu

c Kate Clancy, Food systems consultant, University Park, MD 20782 USA; klclancy@,comcast.net

d Linda Berlin, Center for Sustainable Agriculture, University of Vermont; 23 Mansfield Avenue; Burlington, VT 05401

3323 USA; linda.berlin@uvm.edu commentary, we present and assess the extension and outreach objectives, activities, challenges and outcomes of a complex, inter-disciplinary food systems research project called Enhancing Food Security in the Northeast through Regional Food Systems (EFSNE) project. As an integrated

e Anne Palmer, Center for a Livable Future, Johns Hopkins Bloomberg School of Public Health, 615 N. Wolfe Street W7010; Baltimore, MD 21205 USA; apalmer6@jhu.edu

\section{Disclosure}

This research was supported by U.S. Department of Agriculture National Institute of Food and Agriculture (USDA NIFA) Agriculture and Food Research Initiative (AFRI) grant \#201168004-30057: Enhancing Food Security in the Northeast through Regional Foods Systems. 
project — defined by USDA as including research, education, and extension-EFSNE focused on the regional food system of 12 Northeast states.

EFSNE's Outreach Team met the project's outreach objectives by proactively sharing project findings with multiple audiences including participating low-income communities in a variety of ways. We outline the unique framework and rationale from which multiple outreach activities were conducted during the six years of the project. We also describe challenges we faced along the way, including the tension between research and community engagement, and the translation of complex research to multiple audiences. While complex systems projects often take several years to produce results, we believe that a contextually appropriate, coordinated and meaningful ways throughout the project provides significant benefits to multiple stakeholder audiences as well as to the project itself. We believe this compilation of our outreach strategies may inform similar work in other large, integrated complex regional research projects.

\section{Keywords}

Learning Community; Stakeholder Engagement; Communities of Practice; Community Readiness Model; Systems Modeling, Extension

\section{Introduction}

Complex projects must manage many challenges, including how to communicate with multiple audiences. We present and assess the extension and outreach objectives, activities, challenges and outcomes of a complex, interdisciplinary food systems research project called Enhancing Food Security in the Northeast through Regional Food Systems (EFSNE). As an integrated projectdefined by USDA as including research, education, and extension-EFSNE focused on the regional food system of 12 U.S. Northeast states.

EFSNE was an interdisciplinary project funded by the USDA Agriculture and Food Research Initiative (2011-2017). EFSNE's Outreach Team (OT) employed several creative methods to proactively share findings with multiple audiences and to engage with leaders in the participating communities. We used a common understanding of extension as educational activities that deliver science-based knowledge (research and education) directly to people (USDA National Institute of Food and Agriculture, 2017). Outreach is similarly defined as "efforts to bring services or information to people where they live or spend time" ("Outreach," n.d., para. 1).

The EFSNE Project was designed to assess whether greater reliance on regionally produced foods could improve food access for low incomecommunities in the Northeast while also benefiting farmers, supply chain firms and others in the food system. The project examined structural and community dimensions of certain regionally, nationally, and globally produced and distributed food items. We selected community leaders and storeowners in nine case study locations chosen based on a set of considerations including geographic distribution across the region, rural and urban settings, and demographics/. EFSNE was not a participatory research project in which community stakeholders were part of the design team. Nor did we involve many community members in decision-making or research activities, often referred to as "stakeholder engagement." We did (1) recruit site leaders who helped plan and implement many parts of the project, (2) interview store owners and provide feedback to them on our findings, (3) train and utilize community members to conduct focus groups and administer intercept surveys, (4) conduct community readiness interviews, and (5) host a workshop where community leaders and store owners shared knowledge and experiences with project researchers and each other.

The growing enthusiasm among professional and general audiences toward local and regional food systems created an opportunity for multiple outreach and extension interactions between fellow researchers, NGOs, policymakers, and businesses across the country. To engage these groups meaningfully we had to clearly explain the project's complexities and nuances, paying careful attention to language, vocabulary, and context in all project materials and correspondence.

The EFSNE Project was organized around Production, Distribution and Consumption research teams, and the Scenarios and Models, Education, Outreach, and Evaluation teams. The 
OT was led by a person from outside academia and government, and included several Extension educators and a communication staff person from the host Northeast Regional Center for Rural Development at Penn State University.

While not a participatory research project in which the research planned and conducted with the people whose actions were under study, we sought to be transparent by acknowledging the creative tension between "studying" a community and working with a community in meaningful ways to support its objectives. As one community leader remarked, "It can't just be 'here they [researchers] come again'." Early on, the OT envisioned a "twoway street" approach as essential to the success and legitimacy of the project. This meant not only disseminating knowledge and research highlights but also engaging key audiences. The project depended on the active involvement of communities in nine urban and rural locations across the Northeast, chosen in part based on their potential receptivity to a project like EFSNE.

\section{Strategic Outreach Plan}

This complex and ambitious project required getting a handle on the universe of stakeholders; to identify what behavior(s) we desired from each stakeholder audience, the OT produced a strategic stakeholder matrix. Table 1 shows how different stakeholder groups engaged with the project.

For example, we desired that agri-food entities gain knowledge about the Northeast food system through the newsletter, website, publications, events, and learning communities. We wanted leaders in our community sites to learn more about their food system, participate in and "ground truth" the project's research activities, and when relevant, apply knowledge gained in their own work. The project also developed pathways to the nine project locations. Local leaders were recruited to serve as liaison between the project and specific communities and to help identify study stores, attend project workshops, engage in community focus groups, and organize local project-related "learning community" events. The strategic outreach plan was the roadmap for the project's outreach and extension activities described here.

\section{Events and Online Presence}

Between 2011 and 2016, Team members delivered over 80 presentations and webinars about or related to project research and other activities. The variety of venues (from the American Society of Agronomy to the Transportation Research Board) is a testament to the project's commitment to broad engagement, and conversely to broad interest in EFSNE. A full list is maintained on the project website. ${ }^{1}$ Each project year, EFSNE gave a workshop at the Northeast Sustainable Agriculture Working Group's (NESAWG) "It Takes a Region" conference. Our intention was to distill but not dilute the project's complexities for a diverse audience. Each session was designed to solicit feedback from the audience, which helped the Teams develop a more relevant frame for their work.

In 2013, EFSNE brought community leaders and supermarket owners from several project sites together with EFSNE researchers. This two-day meeting enhanced community leaders' understanding and knowledge of the research and researchers' knowledge and understanding of community efforts and business realities in the project locations. It provided storeowners a platform to share stories with their peers, and a critical business perspective to the research project. Furthermore, it cultivated interest among communities and encouraged their involvement with the project's investigations and their own food system activities.

Not all nine locations were represented however, which prevented the meeting from achieving its full potential, and underscored the persistent challenges in engaging communities in these types of endeavors. Community leaders reported that they felt more empowered and interested to work for changes in food access, and to share project findings. Storeowners reported deep satisfaction in sharing their successes and challenges and interacting with their peers.

In 2015, the OT organized a national conference to share the project with academics, policymakers, government staff, students and community leaders, feature findings to date, showcase and connect "sister" AFRI projects, and gather feedback to inform the project's concluding phase.

${ }^{1}$ http://agsci.psu.edu/research/food-security 
Attendees included USDA senior staff and select professionals and policy leaders in the field.

The project website and email newsletter, while inherently one-way, were effective means of supporting the project's "two-way street" framework. The website enabled all stakeholders to learn about whatever aspects of the project interested them. For instance, community leaders could find information about their locale, learn about communitylevel activities, or download presentation files prepared by team researchers. The website pro- vides a comprehensive and accessible explanation of the project structure, objectives, research activities, and information on locations and study sites.

The project newsletter was a venue for explanatory storytelling about how we were carrying out our work, why we were studying particular issues, and how our findings might be applied in research or policymaking. In writing these stories, we strived to remove barriers preventing those without a scientific background from approaching our research. For example, we featured an article on

\section{Table 1. Stakeholders and Interactions}

\begin{tabular}{|c|c|}
\hline Stakeholder categories & Interactions \\
\hline Academics and Extension & $\begin{array}{l}\text { - Read project publications and/or view presentations } \\
\text { - Attend workshops/national conference } \\
\text { - Attend community/researcher workshop } \\
\text { - Provide feedback } \\
\text { - Join Learning Community and/or Community of Practice } \\
\text { - Keep current with project via website and newsletter }\end{array}$ \\
\hline $\begin{array}{l}\text { Community leaders and groups (specific to EFSNE } \\
\text { sites, and others not related to the project or } \\
\text { necessarily to agriculture and food such as } \\
\text { regional planning agencies) }\end{array}$ & $\begin{array}{l}\text { - Participate in research/community activities including reviewing } \\
\text { surveys and focus group guides } \\
\text { - Attend workshops/national conference } \\
\text { - Attend community/researcher workshop } \\
\text { - Provide feedback } \\
\text { - Keep current with project via website and newsletter } \\
\text { - Consume public coverage (press releases, newswires, etc.) }\end{array}$ \\
\hline Store owners & $\begin{array}{l}\text { - Participate in research (store inventories, supply chain case studies, } \\
\text { etc.) } \\
\text { - Attend community/researcher workshop } \\
\text { - Keep current with project via website and newsletter }\end{array}$ \\
\hline $\begin{array}{l}\text { Agri-food entities (NGOs, businesses, farmer } \\
\text { groups, and food and agriculture networks) within } \\
\text { the Project, the Northeast region, and beyond }\end{array}$ & $\begin{array}{l}\text { - Keep current with project via website and newsletter } \\
\text { - Attend national conference }\end{array}$ \\
\hline $\begin{array}{l}\text { Students (part of EFSNE, others involved in agri- } \\
\text { food research, and others) }\end{array}$ & $\begin{array}{l}\text { - Attend workshops/national conference } \\
\text { - Attend community/researcher workshop } \\
\text { - Read project publications and/or view presentations } \\
\text { - Keep current with project via website and newsletter }\end{array}$ \\
\hline $\begin{array}{l}\text { Funders (Government and agency personnel, as } \\
\text { well as private funding organizations) }\end{array}$ & $\begin{array}{l}\text { - } \text { Contribute resources (financial/other) } \\
\text { - Attend national conference } \\
\text { - Provide feedback } \\
\text { - Keep current with project via website and newsletter } \\
\text { - Read project publications and/or view presentations } \\
\text { - Consume public coverage (press releases, newswires, etc.) }\end{array}$ \\
\hline $\begin{array}{l}\text { Other contemporaneous AFRI Global Food } \\
\text { Security projects }\end{array}$ & $\begin{array}{l}\text { - Keep current with project via website and newsletter } \\
\text { - Read project publications and/or view presentations } \\
\text { - Attend workshops/national conference }\end{array}$ \\
\hline The media & $\begin{array}{l}\text { - Interview team members, attend events, and write and publish news } \\
\text { stories } \\
\text { - Read project website, publications, and/or presentations }\end{array}$ \\
\hline
\end{tabular}


the EFSNE market basket to explain the concept of the market basket research approach, and how the chosen foods related to various project research activities.

\section{Community Readiness Model}

As project researchers interacted with community leaders, it became clear that the communities displayed different capacities to engage in the research activities and/or to conduct community-based "activities." To understand the extent to which communities were-or could be-engaged in food access work, we conducted a "community readiness" study based on the theory that communities progress through stages of change in relation to an issue, as do individuals. The Community Readiness Model (CRM) assesses and builds on how ready a community is to address a social issue (Tri-Ethnic Center, Colorado State University, 2017). Using food access as the topic, a project researcher interviewed four community leaders in each of six project locations to assess organizational resources, capacity and attitudes of their respective communities (Silwa et al., 2011). Leaders described how their communities had addressed food access and what might be appropriate next steps to increase access to healthy food for all community members.

CRM posits six elements of community readiness, and assigns a score based on the interviews. For example, the data showed that the resource, leadership and efforts dimensions consistently yielded higher scores than the knowledge of the issue, knowledge of the efforts and community climate dimensions in all communities. The CRM indicators revealed that project communities have active leaders planning efforts, but with modest community support. The overall readiness scores indicated that the three urban communities were a bit more advanced on the scale than the three rural communities.

The data from the CRM transcripts enhanced the team's understanding of the communities and the larger EFSNE project. They provided descriptive information about programs, policies, leadership and resources that could be leveraged to plan, implement and sustain greater food access. Qualitative data also provided information about each community's challenges and obstacles.

Each location was asked and supported to create a community event that would highlight project findings, encourage communities to use the findings in their work, and enhance understanding of local and regional food system issues. Six locations took different approaches to execute engaging, interactive and place-based initiatives combining project results and local resources to animate the research findings.

\section{eXtension Community of Practice}

EFSNE's core extension commitment was to engage colleagues interested in regional food systems. The OT pursued the Cooperative Extension System's eXtension Community of Practice (eCoP) platform for virtual sharing of information and professional network-building to enhance the work of Extension and other professionals working on local and regional food systems. In 2011 the OT invited colleagues at the University of WisconsinMadison and Ohio State University — where similar eCoP initiatives were being explored-to collaborate. Together we recruited a national Leadership Team for the Community, Local and Regional Food Systems (CLRFS) eCoP which convened in 2012. Penn State University, EFSNE's host institution, received eXtension funding to develop this $\mathrm{eCoP}$, and a national meeting of the CLRFS eCoP was held later that year. Online content development, curation, and publishing began in the following year. A second national meeting was held in 2014. As of 2017, there are over 400 members of the CLRFS eCoP, the second largest in the eCoP stable. A national Leadership Team provides overall direction, with a steering team providing more direct management. Ohio State University Extension provides supporting administration, with hired part-time staff. Eight work groups provide the substance of the community's work.

\section{Food Systems Modeling Learning Community}

The learning community (LC) concept was core to our vision of a compendium of methods to inform, teach, learn and network. Learning communities are groups of people in academic settings who share common interests, and meet regularly or periodically to pursue and exchange knowledge, and to collaborate. The LC framework can be 
especially effective with interdisciplinary groups.

Food systems modeling emerged as a priority LC topic. System modeling is of increasing interest as an analytical tool for food systems researchers and practitioners. Several project researchers were engaged in modeling protocols, which generally aim to generate physical, conceptual or mathematical representations of phenomena to explain and predict the behavior of specific systems. The OT and EFSNE researchers who engage in modeling reached out to academics outside EFSNE who helped develop a food system modeling LC (FSMLC).

One purpose of the FSMLC was to strengthen members' work by providing a skilled and supportive academic community for building expertise, trust and a shared language. The FSMLC enabled both agricultural economic and bio-physical modelers doing work in food systems to share their best practices and challenges. The plan was to then reach out to Extension and other practitioners"consumers" of food system modeling research and tools - to build their literacy to work with modelers. About fifteen academic professionals from across the country initially participated, holding eight webinar-based presentations on their food systems modeling work; more joined the following year. These activities fostered learning and developed trust among colleagues to share achievements and challenges. They also collected resources for engaging practitioners in food systems modeling which will be uploaded to the CLRFS eCoP.

\section{Research Briefs}

A priority extension goal was to make project findings accessible to its multiple stakeholder groups-a formidable challenge considering the highly technical and sometimes arcane research material. Publishing findings in scientific journals was important, but so was making the findings available — and understandable — to general audiences including practitioners and multiple stakeholder groups (see Table 1).

As project results became available, the OT produced research briefs that distill peer-reviewed journal articles authored by project team members into 2-to-4-page general-audience documents. Each brief "decodes" technical language and translates data into common language and/or digestible graphic representations. Briefs describe methods and findings, and discuss their implications and applications. The briefs are disseminated through multiple channels, including the project website and newsletter, the CLRFS eCoP, and NESAWG's website.

\section{Observations, Analysis and Lessons Learned} Overall, the project's multipronged extension efforts were successful, but not without challenges. Our strategic plan framework to achieve multiple objectives with multiple audiences set a strong guiding foundation for outreach. Our outcomes included a wide audience informed and educated about our work and the Northeast food system via multiple formats; target communities more engaged in food system activities and advocacy and constructive partners in research; new approaches for regional food system thinking and networking; and a model for communicating about complex, inter/transdisciplinary integrated projects.

Despite our desire for a "two-way street" we did not receive as much useful input and feedback as we had hoped. Furthermore, engagement with some of our project communities met with several obstacles and disappointments. The research questions were not easily actionable at the community level especially within the project timeline. For example, it was hard to deliver a broad message about regional food systems when most project communities were more focused on "local." Toward the project's end we were more able to integrate the project's work and effectively translate it to the communities. Observations suggest that at least two communities began to integrate the larger picture. Perhaps not coincidentally, these communities scored high in the community readiness assessment.

The tension we anticipated between community development and research turned out to be a reality on the ground. Ours was not a community intervention project, yet we suggested at the outset that we would bring something to communities that would enhance their own interests and efforts. The project did not bridge the gap between the community-as-research-site, communities' local 
focus, and the research's regional scope as well as anticipated. A more appropriate action turned out to be the Community Readiness surveys, which helped community leaders assess — and act onlocal capacity.

Translating the project was a challenge internally and with outside audiences. It was challenging initially for team members to understand the systems nature of the project and then to translate our work to communities and lay audiences. We needed to build internal capacity to translate our work and then apply it to project communities and audiences beyond. As the entire EFSNE team understood how the pieces fit together, we were better able to communicate that externally. For example, a project piece on transdisciplinary research was frequently referred to internally and widely viewed externally. The project requiredand team members benefitted from-intensive internal project communications. The importance of a project communications staff person cannot be overstated. We employed a distributed review process that all project communications were subject to and that team members were expected to participate in. While onerous at times, this process helped ensure message consistency and optimized intra-project learning.

The CLRFS eCoP and the FSMLC proved to be successful and meaningful extensions of the EFSNE project. Each engaged a national network of peers and both have sound prospects for ongoing sustainability. These "legacy spin-offs" achieved an important EFSNE goal-to engage educators, researchers and practitioners in "regional food systems thinking" of which the EFSNE project is a leading example.

\section{Conclusion}

This interrelated compilation of extension and outreach tactics can serve as an example for other inter- and transdisciplinary projects. While complex systems projects often take several years to produce results, communicating about them in appropriate, coordinated and meaningful ways to stakeholders throughout the project provides significant benefits to multiple audiences as well as to the project itself. While we outlined an outreach plan early in the project, we also remained flexible and creative in our execution. For example, the community readiness results elucidated differences among the locations that led to adjustments to the plan. Community events were tailored to stakeholders' interests in project results and implications, rather than based on an assumption that all locations would utilize the research findings. More traditional academic engagement occurred through the national conference and the annual NESAWG conference. Through the eXtentson CoP and the FSMLC, we created virtual opportunities to enhance learning with academic and practitioner communities beyond the Northeast. We believe the compilation of our outreach strategies we present here may inform similar work in other large, integrated complex regional research projects.

\section{References}

Outreach. (n.d.). In Cambridge Dictionary online. Retrieved May 22, 2017, from

http://dictionary.cambridge.org/us/dictionary/english/outreach

Silwa, S., Goldberg, J. P., Clark, V., Collins, J., Edwards, R., Hyatt, R. R.,...Economos, C. D. (2011). Using the community readiness model to select communities for a community-wide obesity prevention intervention. Preventing Chronic Disease, 8(6), A150. Retrieved from http://www.cdc.gov/pcd/issues/2011/nov/10 0267.htm

Tri-Ethnic Center for Prevention Research, Colorado State University. (2014). Community readiness for community change. Retrieved from http://triethniccenter.colostate.edu/communityReadiness home.htm

United States Department of Agriculture, National Institute of Food and Agriculture (USDA NIFA). (n.d.). Extension. Retrieved from https://nifa.usda.gov/extension 